bioRxiv preprint doi: https://doi.org/10.1101/2021.02.05.429744; this version posted February 7, 2021. The copyright holder for this preprint (which was not certified by peer review) is the author/funder. All rights reserved. No reuse allowed without permission.

\title{
Densified Collagen Tubular Grafts for Human Tissue Replacement and Disease Modelling Applications
}

Alexander W. Justin ${ }^{1 *}$, Sebastian Burgess ${ }^{1}$, John Ong ${ }^{1,2}$, Aishwarya G. Jacob ${ }^{3}$, Sanjay Sinha ${ }^{4}$, Athina E. Markaki ${ }^{1 *}$

${ }^{1}$ Department of Engineering, University of Cambridge, Trumpington Street, Cambridge CB2 1PZ, UK.

²East of England Gastroenterology Speciality Training Program, Cambridge, UK.

${ }^{3}$ Wellcome-Medical Research Council Cambridge Stem Cell Institute, Anne McLaren Laboratory, University of Cambridge, Cambridge CB2 0SZ, UK.

${ }^{4}$ Department of Medicine, Division of Cardiovascular Medicine, University of Cambridge, Cambridge CB2 0QQ, UK.

\section{Corresponding Authors: Dr Alexander W Justin (awj27@cam.ac.uk)}

Dr Athina E Markaki (am253@cam.ac.uk)

\section{ABSTRACT}

Fabrication of tubular grafts de novo has been limited by the ability to produce constructs which fulfil the mechanical and biological requirements for implantation and function. In this work, we present a novel method for the formation of densified collagen hydrogel tubular grafts on the scale of human-sized vessels, with the required mechanical strength for future in vivo implantation. The seamless, densified collagen tubes are highly customisable in terms of density, luminal diameter and wall thickness; here we report tubes with luminal diameters $5 \mathrm{~mm}, 2 \mathrm{~mm}$, and $50 \mu \mathrm{m}$, with wall thicknesses of 0.5-3 mm. We show that through genipin crosslinking, acid solubility and swelling of the collagen can be eliminated. Tensile testing shows that axial strength increases with starting collagen and crosslinker concentrations. The cell-compatible densification method enables a high density and uniformly distributed population of cells to be incorporated into the walls of the construct, as well as onto the luminal surface. Additionally, we report a method for generating tubes consisting of distinct cell domains in the walls. The cellular configurations at the boundary between the cell populations may be useful for disease modelling applications. We also demonstrate a method for luminal surface patterning of collagen tubes.

Keywords: Densified collagen, tissue engineering, vascular grafts, tubular scaffolds, disease modelling

\section{INTRODUCTION}

Tissue engineering seeks methods for the generation of bioengineered tubular grafts, to serve as replacement conduits to meet a growing clinical need [1]. This includes blood vessels (e.g. coronary and peripheral arteries, arterio-venous grafts and fistulas for hemodialysis) [2-6], the bile duct [7, 8], small and large intestine [9-11], oesophagus [12, 13], genitourinary [14] and tracheobronchial [15-18] systems, and guiding conduits for peripheral nerves [19]. Researchers also seek artificial tissue for disease modelling in vitro [20-22], such as for vascular smooth muscle behaviour in atherosclerosis [23] and Marfan disease [24], in which three-dimensional (3D) cell culture systems can recapitulate the native cell response in the extracellular matrix (ECM).

Tubular grafts have been generated via processing of a wide range of materials, including synthetic materials (polyester, polyurethane), cadaveric tissue, or biomaterials such as collagen and fibrin, as well as scaffold-free approaches [2426]. Scaffolds derived from decellularised cadaveric tissue [27], while providing a high degree of bioactivity and innate vascularisation, are limited in availability and customisability in terms of density, shape, and composition. Syntheticbased scaffolds, while inexpensive and simple to manufacture, frequently lack the biological niche and degradation characteristics for cellular repopulation and remodelling. To overcome this, a common approach is to use cells, seeded 
upon a synthetic porous scaffold, to produce native ECM (e.g. human acellular vessels) [28, 29]. Ideally, the fabrication of tubular grafts without the use of cells via fully definable and patient-derivable biomaterials would limit the immunogenicity of the construct.

The method of generating tubular grafts must be amicable to cell seeding both onto the surface and uniformly in the walls of the tissue, allow for cellular remodelling, provide suitable and tuneable mechanical properties to match native tissue, and importantly be scalable from small animal models to human vessel dimensions. Tissue-specific challenges must also be addressed, such as thrombogenicity in blood vessels or acidity in urothelial conduits. Furthermore, many tissues will require the incorporation of organoids to recapitulate tissue function and so require a cell-compatible manufacturing process. Intestinal grafts also require fabrication methods to generate the high surface area and rich vasculature necessary for physiological function.

Methods for producing collagen-based grafts specifically include freeze-drying (yielding mechanically weak and highly porous sponges) [9, 30], electrospinning (high density of collagen, limited cellular remodelling and infiltration) [31], or through a hybrid with synthetic materials in which the synthetic provides the mechanical support for the collagen or ECM [32]. Alternatively, collagen hydrogel approaches support high bioactivity and consist of a macromolecular network of collagen fibrils which retain a significant volume of water. However, a standard collagen gel is mechanically weak and high collagen concentrations are difficult to deploy owing to high viscosity and rapid gelling times. Further, collagen fibrils are randomly orientated. In the native ECM, collagen density is significantly higher, and fibrils are hierarchically organised and aligned over distance which, alongside native crosslinking mechanisms, provide the tissue with mechanical support.

Several techniques [33-39] have been investigated to produce tubular collagen grafts by increasing the fibril alignment and density of a collagen hydrogel, thereby producing a mechanical robust construct while still retaining high bioactivity. This is achieved by removing a large fraction of the interstitial water from the hydrogel through 'plastic compression' [34, 36], air drying [39], rotation-based water loss [38], gel compaction driven by cell traction forces [35] or cyclic straining [33]. Collagen grafts have also been produced by the rolling of densified collagen sheets, but this leads to the formation of seams [37]. Many of the resultant tubes tend to be thin-walled [33, 35, 36, 38], failing to match the wall thickness of human vessels, and are not easily scalable to human-sized vessels.

We have developed a novel method for the formation of tubular densified collagen hydrogel grafts which allows for densification in both the axial and radial directions, using a funnel-shaped mould. This results in mechanically robust tubes which are widely customisable in terms of tube diameter, wall thickness and collagen concentration. Tubes can be manufactured acellular or cellularised by uniformly seeding cells into the walls of the conduit prior to collagen gelation and densification, or by seeding cells onto the luminal surface after the densification process is complete. Furthermore, the densification method is applicable to both small animal and human-sized conduits. To stabilise the collagen structure against acid degradation (e.g. urea) and to closer match the mechanical strength of real tissue, we further crosslink the densified collagen tubes using genipin, a biocompatible crosslinking agent which can be used in the presence of embedded cells.

Additional steps to the standard technique enable more niche and disease modelling applications to be targeted. The shape of the funnel can be used to produce constructs with a gradient or uniform collagen concentration along their length. Also, by casting collagen in sequential steps, one can produce tubes with distinct cellular domains, which may be useful in disease modelling involving boundaries between cell types. Indeed, we show a spatial organisation of cells 
near the boundary which is highly reminiscent of the organisation of smooth muscle cells (SMCs) in the proximal aorta (neural crest origin and lateral plate mesoderm) and thus may be useful for studying aortic aneurysms. Additionally, ultra-fine conduits can be generated using pre-densified constructs and applying an additional air-drying step. Finally, we have developed methods for patterning the luminal surface which may support the future generation of intestinal crypt-villus structures.

\section{MATERIALS AND METHODS}

\subsection{Materials}

Collagen solution was generated from rat tail tendons using a known method [40]. Briefly, frozen rat tails were purchased (Blue Lizard Reptiles) and the tendons excised. Following $72 \mathrm{~h}$ in $0.02 \mathrm{M}$ acetic acid solution at $4{ }^{\circ} \mathrm{C}$, the solution was centrifuged at $7500 \mathrm{~g}$ for $90 \mathrm{~min}$ and freeze-dried. After weighing the dry mass of collagen, it was resuspended at $10 \mathrm{mg} / \mathrm{mL}$ in $0.02 \mathrm{M}$ acetic acid solution and stored at $4{ }^{\circ} \mathrm{C}$.

Collagen gel was generated using a known method [41]. Briefly, for preparation of $5 \mathrm{mg} / \mathrm{mL}$ collagen precursor solution $(20 \mathrm{~mL}$ ), the reagents used were: 10x M199 medium (Sigma, $2 \mathrm{~mL}$ ), $1 \mathrm{M} \mathrm{NaOH}$ (Sigma, $0.250 \mathrm{~mL}$ ), stock $10 \mathrm{mg} / \mathrm{mL}$ collagen solution $(10 \mathrm{~mL}$ ), sodium bicarbonate solution (Sigma, $0.6 \mathrm{~mL}$ ), penicillin-streptomycin (Sigma, $0.2 \mathrm{~mL}$ ), amphotericin-B (Sigma, $0.2 \mathrm{~mL}$ ), and cell medium $(6.75 \mathrm{~mL}$ ). Viscous collagen solution was transferred using a $10 \mathrm{~mL}$ syringe and added last. The solution was shaken vigorously until thoroughly mixed and centrifuged at $4000 \mathrm{~g}$ for $10 \mathrm{~min}$ at $4{ }^{\circ} \mathrm{C}$.

Perspex chambers, for casting and collagen densification, were machined to tube specifications, consisting of a funnel section and cylindrical section, and a flange base. The internal surfaces were polished to remove machining marks (Euro Car Parts). Additionally, a lid piece and jig piece were machined from Perspex, and Perspex, PTFE and nylon rods were purchased to size (Engineering \& Design Plastics). Nylon membranes were used with a pore size of $1.2 \mu \mathrm{m}$ and $5 \mu \mathrm{m}$ (Millipore).

\subsection{Manufacturing method}

Perspex funnels and additional components were immersed in ethanol and dried prior to experiments. Internal funnel surfaces were coated in sunflower oil using paper towels (Kimwipes) and positioned upside down. A ring of dental silicone (Billericay Dental Supply Co.) was placed around the central hole and a $1.2 \mu \mathrm{m}$ nylon membrane was positioned over the hole. A machined, Perspex jig was placed over the chamber flange to flatten the membrane and silicone. A locating hole at the centre of the jig provided alignment in the centre of the casting chamber for a biopsy punch (Agar Scientific) which produced a hole to match the diameter of the central rod (e.g. $2 \mathrm{~mm}, 5 \mathrm{~mm}$ ). The jig was then removed and, using a further silicone ring, a second $1.2 \mu \mathrm{m}$ membrane was fixed over the top, using the jig once again to flatten the silicone and membrane. Membranes and funnel were subsequently pre-wetted with sterile phosphate-buffered saline (PBS,Sigma) to liberate any trapped air bubbles between the membranes. Collagen precursor solution was prepared as described above and transferred to the funnel.

The collagen solution was visibly clear of air bubbles after centrifugation. Failure to remove all the bubbles led to suboptimal tubes with high numbers of defects or could disrupt the densification process entirely. The collagen solution was poured very slowly down one side of the internal funnel surface, thereby preventing any mixing of the oil and collagen solution and preventing any turbulence which may trap air bubbles. The pre-wetted membranes allow the infiltration of collagen solution, which subsequently provides a gripping point for the collagen gel. Once the whole collagen solution 
was in the funnel, the central rod was slowly lowered into the chamber and interlocked into the locating hole in the top membrane, providing alignment to the rod from below. A second Perspex jig provided central alignment from above.

The whole assembly was then left at room temperature or in a $37^{\circ} \mathrm{C}$ incubator for 30 min to allow the collagen to gel. $3 \mathrm{~mL}$ of sterile PBS was pipetted into a small circle at the centre of a large stack of paper towels and the funnel assembly was subsequently positioned on top. A square of Parafilm was placed over the outer surface of the top jig. Once the collagen had gelled, the central rod was gently rotated from above to break any initial bond with the collagen gel. The full assembly was then placed in a $37^{\circ} \mathrm{C}$ incubator, for $6-24 \mathrm{~h}$ for the collagen gel to densify. After densification, the densified collagen tube was carefully extracted from the cylindrical section and subsequently stored under PBS or cell medium. To undertake an additional evaporative densification step, the central rod was not removed from the lumen of the collagen tube and the assembly was suspended horizontally under a biological cabinet for $6 \mathrm{~h}$ to allow for air drying. Following this, the rod and collagen tube were placed into sterile PBS for 30 min which allows the collagen tube to be safely removed from the central rod without damage.

\subsection{Second harmonic generation imaging of tube samples}

Planar strips of collagen were cut from the full length of the tubes. Samples were mounted between two \#1.5 glass coverslips, supported by a silicone spacer, and the coverslip ends were taped together. Inverted Leica TCS SP5 acousto-optic beam splitter (AOBS) multiphoton laser scanning microscope equipped with a Modelocked Ti:Sapphire Laser was used for second harmonic generation (SHG) imaging, with the excitation laser (Ti:Sapphire) tuned to 880 $\mathrm{nm}$. At this specific excitation wavelength, the wavelength of the emitted SHG signal was at $440 \mathrm{~nm}$. A 20x objective was used to focus the excitation beam on the sample and to collect backscattered emission signals which are delivered through the AOBS and the fully opened confocal pinhole $(600 \mu \mathrm{m})$ to the spectral detection system (descanned pathway). Highly specific SHG images were obtained through a 430-450 nm emission bandwidth channel detected on a hybrid detector (HyD, gain $=150 \%$, grey scale). Tiled images were subsequently analysed using ImageJ.

\subsection{Genipin crosslinking}

Genipin (Bioserv UK) was resuspended in sterile PBS at 1 and $10 \mathrm{mM}$ concentrations. Samples of densified collagen tube were immersed in genipin solutions and placed on an orbital shaker for $24 \mathrm{~h}$ at room temperature, followed by a further $24 \mathrm{~h}$ in sterile PBS. Biocompatibility testing of $1 \mathrm{mM}$ genipin solutions with collagen tubes seeded with cells was performed using cell medium containing dissolved genipin. Tubes were immersed in cell medium containing genipin and left in an incubator at $37^{\circ} \mathrm{C}$ for $24 \mathrm{~h}$.

\subsection{Axial tensile testing}

Tensile testing was carried out with an Instron desktop testing machine, fitted with a $5 \mathrm{~N}$ load cell. The tubes were cut along their length and 'unwrapped' so that they were planar. Using a metallic die, rectangular dogbone samples were cut along the long axis of the unwrapped tubes, with gauge sections $7 \mathrm{~mm}$ long, $3 \mathrm{~mm}$ wide and $1.5 \mathrm{~mm}$ thick. For tensile testing of crosslinked samples, dogbone specimens were cut from the tubes prior to crosslinking. The samples were mounted using superglue into paper tabs with a central cut-out. The top end of the paper tab was gripped using a bulldog clip and the bottom end using a specially designed vice clamp grip that used a pivot action to initially grip the sample and a clamping screw to tighten the vice. The jaws of the grip were rubber-faced to prevent sample slippage. Prior to testing, cuts were made from each side of the central cut-out. The crosshead displacement was measured using a linear variable differential transformer (LVDT). All tests were conducted in displacement control at a rate of $1 \mathrm{~mm} / \mathrm{min}$. At least 3 samples were tested from each group. 
bioRxiv preprint doi: https://doi.org/10.1101/2021.02.05.429744; this version posted February 7, 2021. The copyright holder for this preprint (which was not certified by peer review) is the author/funder. All rights reserved. No reuse allowed without permission.

\subsection{Solubility tests}

Representative samples cut from uncrosslinked and genipin-crosslinked densified collagen tubes, alongside samples of excised pig vena cava (Medical Meats), were immersed in $100 \mathrm{mM}$ acetic acid solution. A change in mass was measured over a $2 \mathrm{~h}$ period for uncrosslinked samples and over several days for crosslinked tube and excised vena cava samples, using a mass balance with a precision of $0.1 \mathrm{mg}$ and removing the fluid at regular timepoints. However, as the uncrosslinked samples swelled and dissolved, it was not possible to reliably remove all the surrounding fluid without also removing the dissolving collagen.

\subsection{Cell culture and characterisation}

Human liver cancer cells (HepG2s) were cultured in DMEM+10\% FBS. Green fluorescent protein (GFP) and Red Fluorescent Protein (RFP) human umbilical vein endothelial cells (HUVECs, Promocell), normal human lung fibroblasts (NHLFs, Promocell) and mesenchymal stem cells (MSCs, Promocell) were cultured in their respective proprietary mediums (Promocell). Smooth muscle cells (SMCs) were derived from human embryonic stem cells (H9) via the neural crest or lateral plate mesoderm intermediates using established protocols $[42,43]$ and were subsequently cultured in standard medium (DMEM+10\% FBS). Cells were cultured until 90\% confluency and detached from T75 flasks using TrypLE (Life Technologies). Cells were centrifuged at $250 \mathrm{~g}$ for $5 \mathrm{~min}$ and counted using a haemocytometer.

Densification experiments where cells were encapsulated into the walls of the tubes were performed at $2-8 \times 10^{6}$ cells per tube (i.e. $1-4 \times 10^{5}$ cells $/ \mathrm{mL}$ for $20 \mathrm{~mL}$ precursor solution), using collagen tubes with luminal diameters of 2 and $5 \mathrm{~mm}$. Tubes with cells encapsulated in the bulk of the tubes were prepared using either HepG2s, NHLFs, GFP HUVECs and RFP HUVECs, or SMCs. The collagen precursor solution was prepared as above, subtracting a volume for the addition of cells later, and was subsequently centrifuged at $4000 \mathrm{~g}$ for $10 \mathrm{~min}$. 2-3 mL of collagen, without cells, was poured into the funnel to fill the cylindrical section. Doing so prevents the clogging of the membrane with cells and results in all the cells being present in the final tubular construct. The resuspended cell pellet was then pipetted on top of the precursor gel solution. Using a sterile metal spatula, the cells were then slowly mixed into the gel precursor solution until uniform, and the solution was then poured into the funnel assembly as described above. For experiments with cells seeded into the bulk of the collagen gel, the funnel assembly was transferred to a $37^{\circ} \mathrm{C}$ incubator for rapid gelation.

For densified collagen tubes with two distinct cell domains, two $10 \mathrm{~mL}$ collagen precursor solutions were prepared. Prior to adding cells, $1.5 \mathrm{~mL}$ from each precursor solution was transferred into the chamber. GFP and RFP HUVECs were subsequently stirred into their respective precursor solutions and slowly poured into the chamber, one after the other. As with above, the funnel assembly was transferred to a $37^{\circ} \mathrm{C}$ incubator straight after assembly to prevent sedimentation and cell mixing.

HepG2s were used for experiments where cells were seeded upon the luminal surface of the tubes. Using a two T75 flasks, two lots of $50 \times 10^{6} \mathrm{HepG} 2$ cells were pelleted and resuspended in $50 \mu \mathrm{L}$ of Dulbecco's Modified Eagle Medium (DMEM). The $2 \mathrm{~mm}$ luminal diameter collagen tube was cut to length using small scissors and a sterile metal $2 \mathrm{~mm}$ diameter dowel pin (Accu) was positioned in the lumen at one end. Immersing the tube in DMEM, cells were transferred to the tube using a $1 \mathrm{~mL}$ syringe fitted with a $27 \mathrm{G} \times 1.5$ in needle (Medisave). The cell-ladened tube was left in a $37^{\circ} \mathrm{C}$ incubator for $6 \mathrm{~h}$ and then a second volume of HepG2s was added. Over several days, the attached HepG2s proliferated on the luminal surface. 
Cell characterisation was performed via calcein AM staining (Life Technologies). For bulk seeding experiments, the cells were either stained prior to encapsulation or after the densification process. Briefly, calcein AM was resuspended at $4 \mathrm{mM}$ in PBS. Cells plated in T75 flasks, or cell-seeded tubes, were washed in PBS and incubated in a $4 \mu \mathrm{M}$ calcein AM solution in PBS, at $37^{\circ} \mathrm{C}$ for 20 min. For luminal surface seeding experiments, HepG2s were stained prior to seeding. Cell-ladened tubes were imaged using an epi-fluorescence microscope (Zeiss Axio-Observer.Z1).

\subsection{Luminal surface patterning process}

Inverse 3D printed wax models (Solidscape) were prepared using a standard method [44]. 20\% (w/v) high bloom, porcine gelatin solution was poured into the wax moulds and degassed using a vacuum pump. A polished nylon rod, $2 \mathrm{~mm}$ in diameter with a cutaway section at one end with $0.5 \mathrm{~mm}$ diameter, was then fitted through the wax mould and the assembly left at $4{ }^{\circ} \mathrm{C}$ to allow for gelatin gelation. The construct was subsequently immersed in acetone solution to dissolve the 3D printed wax mould and washed in PBS. Following the axial densification protocol as above, the nylon rod, with patterned gelatin gel, was used as a replacement for the Perspex central rod. Once the collagen has gelled, the central rod can be rotated as described above. Following densification of the collagen gel, the tube with patterned gelatin was placed in a PBS bath at $37^{\circ} \mathrm{C}$ to melt the gelatin and allow it to diffuse away.

\section{RESULTS}

\subsection{Novel densification process to form densified collagen tubes}

Collagen gel-based tubes were manufactured using a novel method. A collagen gel precursor solution was cast between a central rod and a funnel-shaped chamber, and the water removed from the gel via a pair of hydrophilic nylon membranes at the bottom of the chamber (Figure 1(a)). The funnel serves to feed a large volume of collagen gel into a defined cylindrical space and the shape of the funnel determines the tube length and uniformity of collagen density in the final tubular construct.

A pair of membranes, with pore size $1.2 \mu \mathrm{m}$, was used to anchor the collagen gel at the base of the funnel-cylinder mould, which controls the rate of water removal and also makes it possible to align the central rod in the chamber with a high degree of precision, enabling fine wall thicknesses to be produced. If a membrane is not used at the bottom of the chamber, the collagen gel rapidly contracts upwards through the cylindrical mould as the water is removed, which has the effect of preventing any further water removal from the gel.

As water is removed from the bottom of the chamber, water percolates through the pores of the collagen gel, leading to the contraction of the polymeric phase downwards into the cylindrical section and alignment of the collagen fibrils (Figure 1(b)). It is critical to this process that the collagen gel is able to glide over the casting chamber surface and so a layer of oil lubricant is applied to the inside of the funnel. Without this, there is sufficient friction between the collagen gel and chamber to prevent the deformation of the collagen gel; this leads to water removal only from the volume of gel contained in the cylindrical section. This causes the collagen gel there to densify radially inwards and pulling air bubbles in through the membranes, preventing any further removal of water from the bulk of the gel contained in the funnel section.

\subsection{Different funnel geometries lead to a uniform or gradient of collagen density in the final structure}

Two different funnel shapes were considered, with identical cylindrical mould sections, which led to different tubular structures after densification, for a given starting volume and concentration of the collagen gel precursor (Figure 1(c-f)). The first (designated as Funnel A) leads to longer tubes with a density gradient along their length; the top part was found to be denser than the bottom (Figure S1). The second design (designated as Funnel B) leads to tubes of uniform 
density, though the result is a shorter tube. Thus, the differences in the final tubes, in terms of tube length and collagen density, can be attributed to differences in the funnel geometries.

(a)

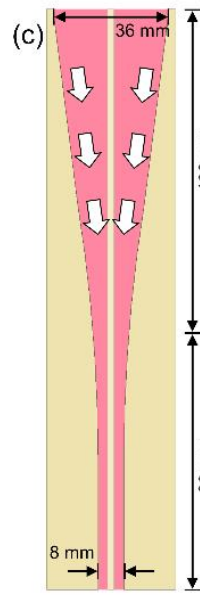

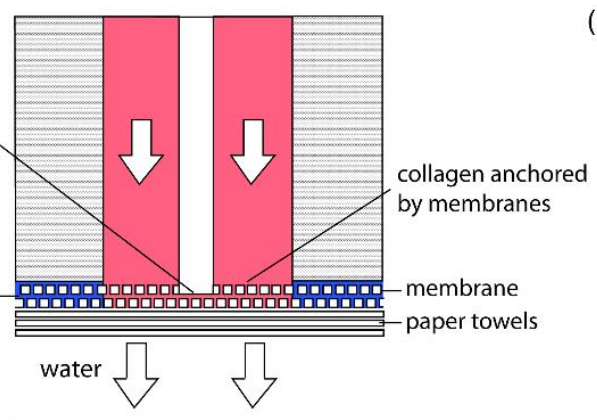

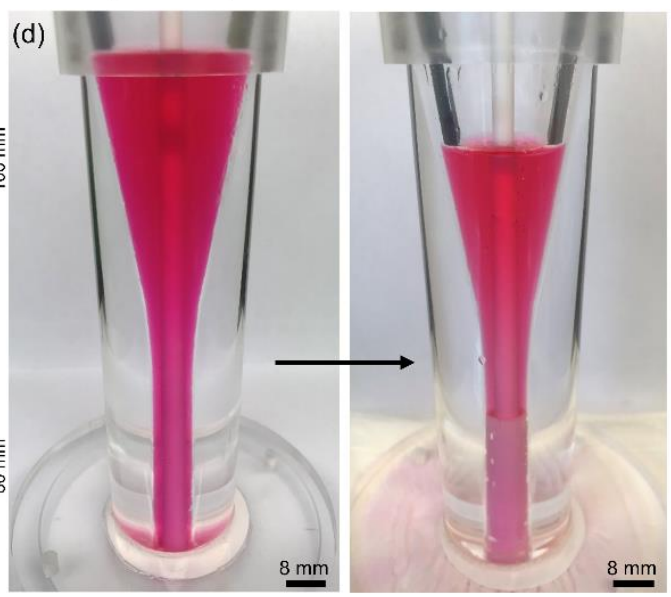

(b) casting

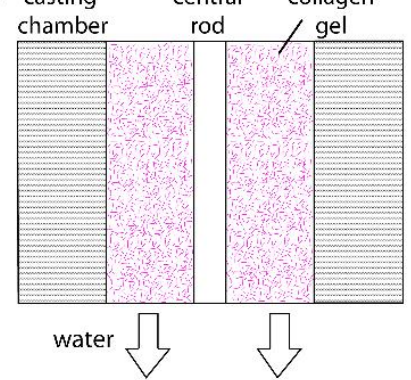

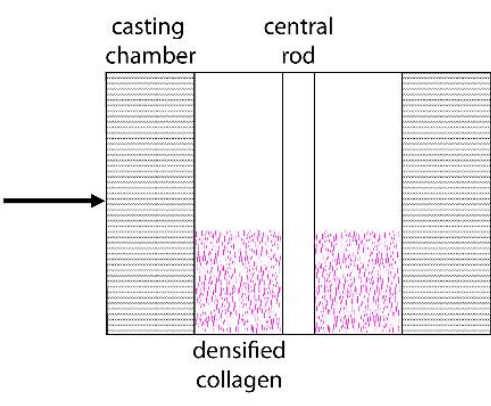

(e)

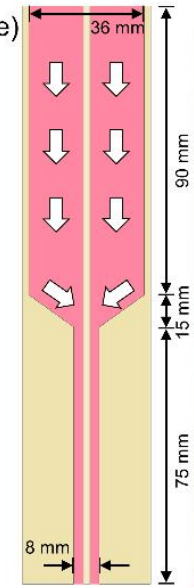

(f)

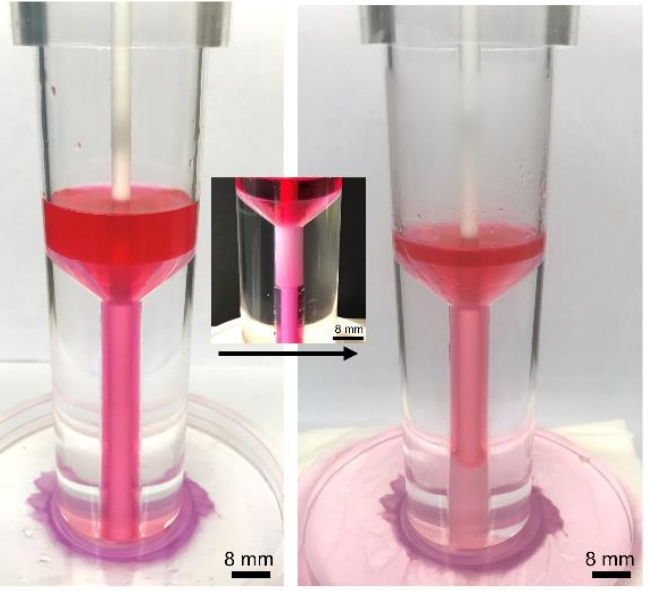

Figure 1: (a) Schematic depiction of the funnel base used for production of densified collagen tubes, showing the cylindrical section of the casting chamber, membrane configuration, central rod alignment, and water removal into paper towels. (b) Schematic showing axial densification of the collagen gel resulting in alignment of fibrils in the axial direction (i.e. long axis of the tubes). (c) Schematic depiction of Funnel A with dimensions. (d) Densification of $5 \mathrm{mg} / \mathrm{mL}$ collagen gel into tubular structure using Funnel A. (e) Schematic depiction of Funnel B with dimensions. (f) Densification of $5 \mathrm{mg} / \mathrm{mL}$ collagen gel into tubular structure using Funnel $B$. The initial volume of collagen gel for both funnels was $20 \mathrm{~mL}$. Inset shows boundary between densified and undensified collagen gel during densification process.

\subsection{Variation in the luminal diameter of densified collagen tubes}

Collagen tubes were manufactured over a range of lumen diameters and wall thicknesses. Typically, tubes of $5 \mathrm{~mm}$ (Figure 2(a)) and $2 \mathrm{~mm}$ (Figure 2(b)) luminal diameter were manufactured, while we also showed that tubes with very small luminal diameters, such as $50 \mu \mathrm{m}$, are possible with this technique (Figure 2(c)). While the luminal diameter and outer diameter are highly customisable, there is a minimum wall thickness (e.g. $0.5 \mathrm{~mm}$ ) below which water removal is excessively slow and for which the central rod would need to be aligned to an unreasonable degree of precision. Second harmonic generation (SHG) imaging of the collagen tubular wall (Figure 2(d)) revealed that the fibres (bundles of densely packed fibrils) are aligned in the axial direction (i.e. the long axis of the tubes) and displayed a uniform fibre density along the tube length for Funnel B.

For tubes with relatively small luminal diameters (e.g. $50 \mu \mathrm{m}, 2 \mathrm{~mm}$ ), we were able to employ a further densification step through evaporative drying (Figure 2(e,f)). Attempts at air drying tubes without a prior axial densification step led to rips in the luminal surface and a non-uniform, mechanically weak tube. However, once the standard densification process is completed, the tubes have sufficient mechanical strength to be suspended from the central casting rod (e.g. a $50 \mu \mathrm{m}$ diameter suture or $2 \mathrm{~mm}$ diameter rod) which makes it possible to air dry the tubes further to produce very small wall thicknesses. The degree of reduction in the wall thickness is a function of the starting collagen gel concentration. By tailoring a low starting collagen concentration, a tube could be manufactured with a very fine luminal 
diameter with a similar wall thickness. This radial densification induces a further increase in the global collagen density, accompanied with a corresponding increase in mechanical strength. While the chamber densification method forms tubes with a uniform wall thickness, evaporative drying can introduce variation in the wall thickness around the tube. This is because the air flow configuration around the tube likely influences the rate of evaporative drying.

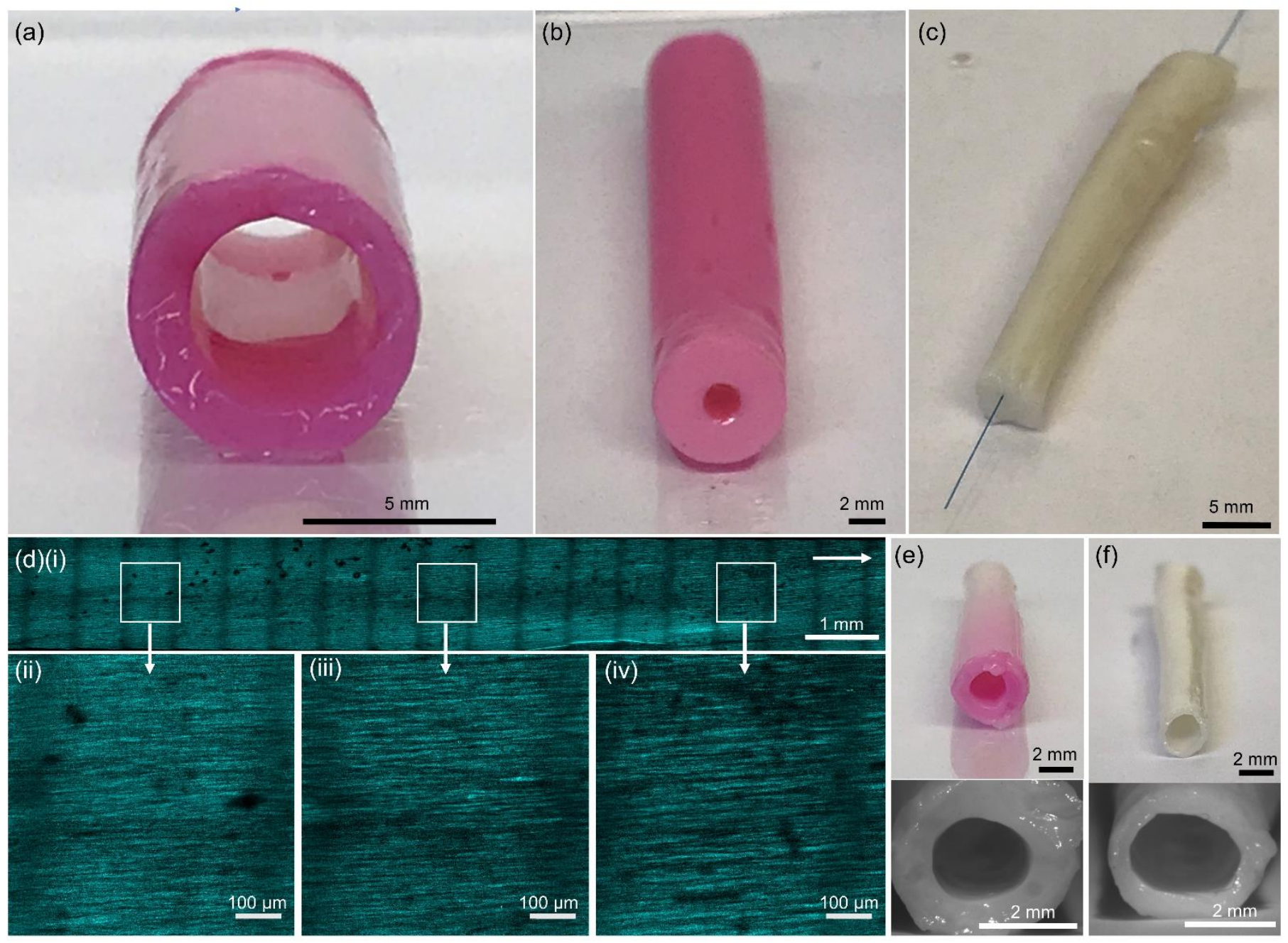

Figure 2: Densified collagen tube examples. (a) $5 \mathrm{~mm}$ luminal diameter and $1.5 \mathrm{~mm}$ wall thickness; (b) $2 \mathrm{~mm}$ luminal diameter with $2.5 \mathrm{~mm}$ wall thickness; (c) $50 \mu \mathrm{m}$ luminal diameter with $2.5 \mathrm{~mm}$ wall thickness. (d)(i-iv) Sample of funnel B displaying fibre orientation and uniform fibre density, as shown using second harmonic generation microscopy. Arrow denotes axial direction (long axis of the tube). Evaporative drying leads to finer wall thicknesses: (e) 2 mm luminal diameter with $1 \mathrm{~mm}$ wall thickness; (f) $2 \mathrm{~mm}$ luminal diameter with $500 \mu \mathrm{m}$ wall thickness. Insets show higher magnification cross-sections.

\subsection{Effect of collagen starting concentration on tube length and final collagen concentration}

The final length of the densified collagen tubes, and thus the final concentration of collagen, is dependent upon the starting concentration of collagen and the choice of funnel geometry (Figure $3(a, b)$ ). Tubes made using a precursor solution of $2.5 \mathrm{mg} / \mathrm{mL}$ collagen produced the shortest tubes, for a given starting volume. Water can percolate through the gel more rapidly and this leads to rapid changes in gel shape. However, such tubes are only able to maintain an open lumen under fluid (requiring the additional evaporative drying step to achieve this in air). A gel precursor solution with a $7.5 \mathrm{mg} / \mathrm{mL}$ starting concentration was hard to cast due to its high viscosity and a high propensity to trap air bubbles leads to many defects. Thus $5 \mathrm{mg} / \mathrm{mL}$ gels were considered optimal for the casting and densification process (relatively low viscosity, low number of trapped air bubbles, longer working time before gelation) and produced tubes capable of supporting an open lumen in air. 


\subsection{Genipin-crosslinked densified collagen tubes}

While the tubes display suitable mechanical strength for handling and cell seeding, crosslinking was investigated in order to imitate the mechanical strength of real tissue and eliminate any swelling and dissolution behaviour of collagen in acidic conditions (i.e. for clinical applications where the perfusate is acidic). Crosslinking was performed using genipin at a biocompatible concentration of $1 \mathrm{mM}$, suitable in tubes where cells have been pre-seeded into the walls of the scaffold, or $10 \mathrm{mM}$, producing mechanically strong structures.

(a)

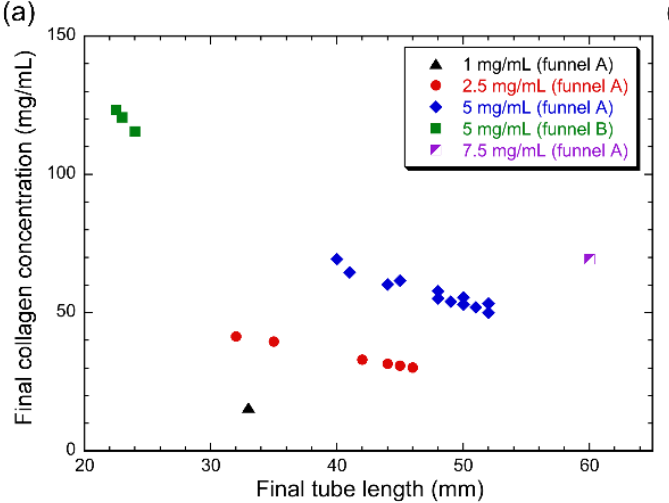

(b)

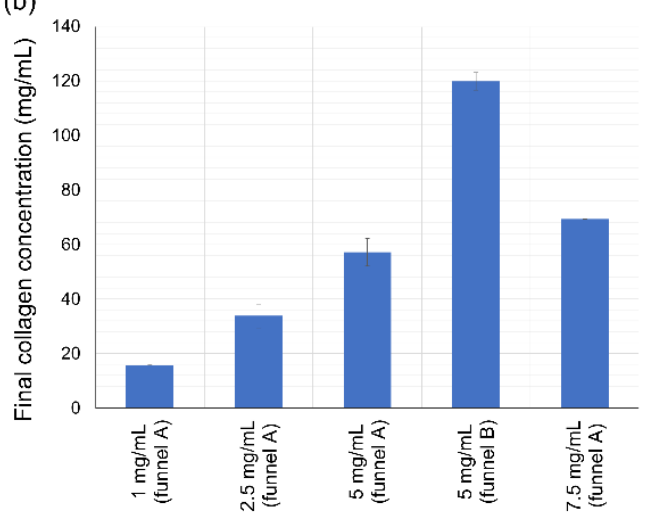

(c)

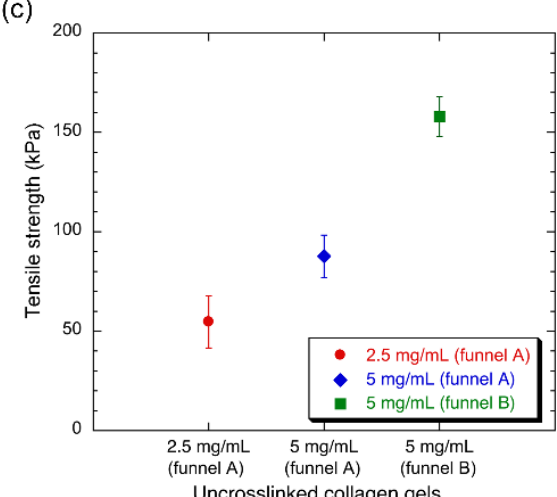

(e)

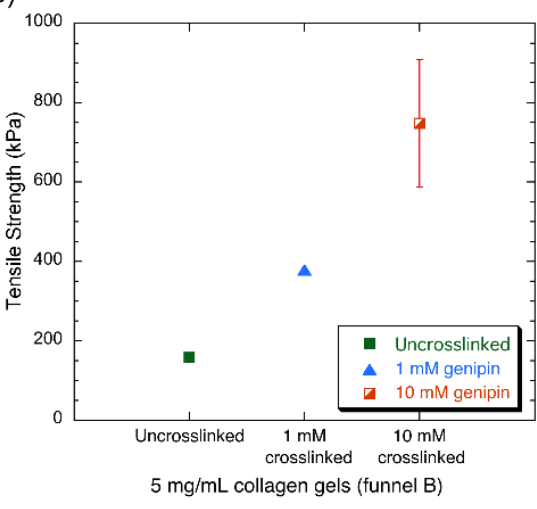

(d)

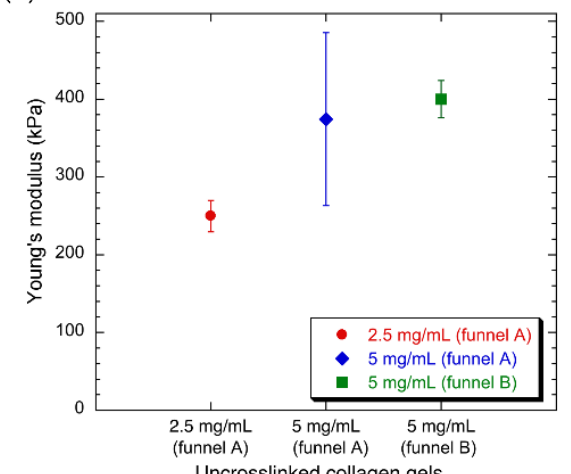

(f)

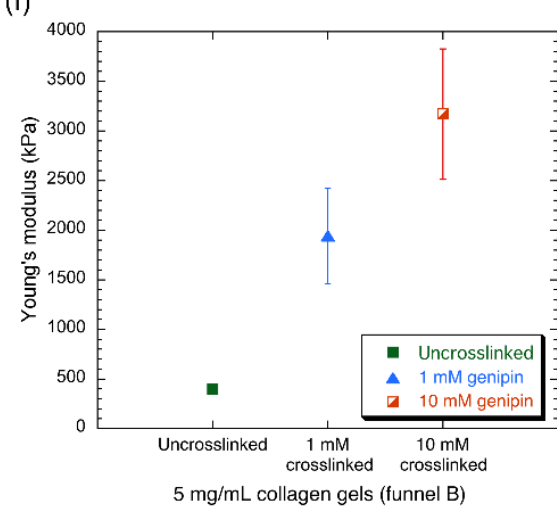

Figure 3: (a) Graph displaying final collagen concentration as a function of final tube length, for tubes produced with Funnels $A$ and $B$ and for different starting collagen concentrations. (b) Final collagen concentrations for a range of starting collagen concentrations, and for tubes produced with Funnels A and B. Measured (c) tensile strength and (d) Young's modulus for uncrosslinked collagen tubes produced with Funnels $A$ and $B$, for a range of starting collagen concentrations. Measured (e) tensile strength and (f) Young's modulus for tubes with $5 \mathrm{mg} / \mathrm{mL}$ starting collagen concentration and using funnel B, comparing uncrosslinked, $1 \mathrm{mM}$ and $10 \mathrm{mM}$ genipin samples. Data (c-f) are obtained from tensile testing planar samples obtained from the tubular walls. Data for tensile strength and Young's modulus are presented as the mean \pm standard deviation $(n \geq 3)$.

\subsection{Axial tensile testing of densified collagen tubes}

The strength and Young's modulus of the uncrosslinked and crosslinked tubular walls were measured using dogboneshaped specimens. The direction of loading was parallel to the long axis of the tubes, which is also the collagen fibril orientation as shown in Figure 2(d). The nominal stress-strain curves show a 'toe' region, followed by a linear region. The Young's modulus was measured from the tangent slope of the linear region of the curve.

The results showed that the initial collagen concentration, the choice of funnel geometry and the crosslinker concentration influence the strength of the tubes. The axial tensile strength (Figure 3(c,e)) was found to increase with starting collagen concentration (hence final collagen concentration) and genipin crosslinker concentration. Higher strength was observed for collagen tubes produced using Funnel B compared to Funnel A (Figure 3(c)). While both tubes have the same starting volume and concentrations, Funnel $B$ leads to shorter, denser (more fibrils per unit volume) 
and hence stronger tubes. The Young's modulus was very similar for uncrosslinked collagen over the concentrations tested (Figure 3(d)) and was found to increase with crosslink density (Figure 3(f)).

Direct comparison with previous work is hampered by a number of disparities between tubes (e.g. starting collagen concentration, method and degree of densification, and crosslinking when applied), testing configuration (e.g. tube, sheet) and loading conditions (e.g. loading rate, a priori cyclic straining to further strengthen the collagen, wet or quasidry state). By limiting the comparison to quasi-testing of rat tail collagen scaffolds, our strength and Young's modulus values compare favourably with previous work $[45,46]$, in which collagen sheets, strengthened by 'plastic compression' (uniaxial compression) were also extracted from the tubes and tested. Further, genipin crosslinking had a comparatively higher impact on the tensile strength of our tubes than previous work on collagen-chitosan-elastin scaffolds [47, 48], which reported an increase in tensile strength by a factor of 2.3 and 2.5 for 1 and $10 \mathrm{mM}$ genipin concentrations respectively, while we report a factor of 2.6 and 4.7 respectively (compared to uncrosslinked samples).

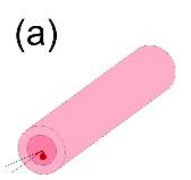

Cells transferred to lumen

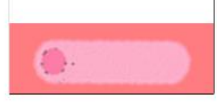

Tube cultured under medium

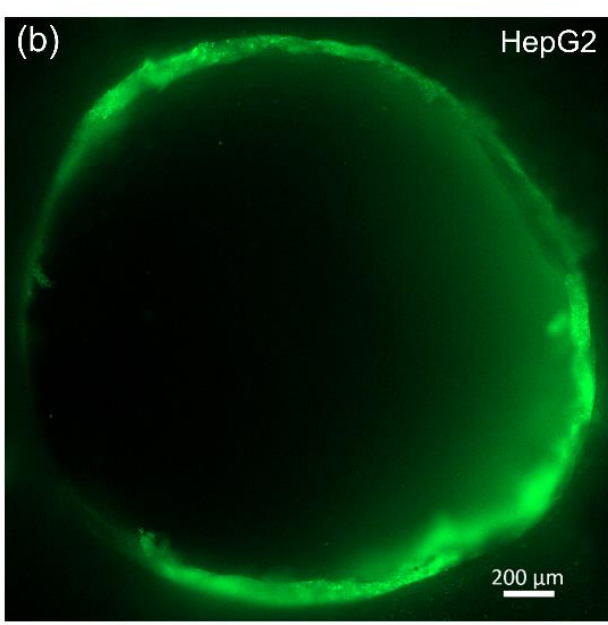

(c)

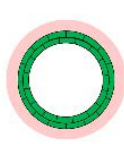

HepG2 cell layer
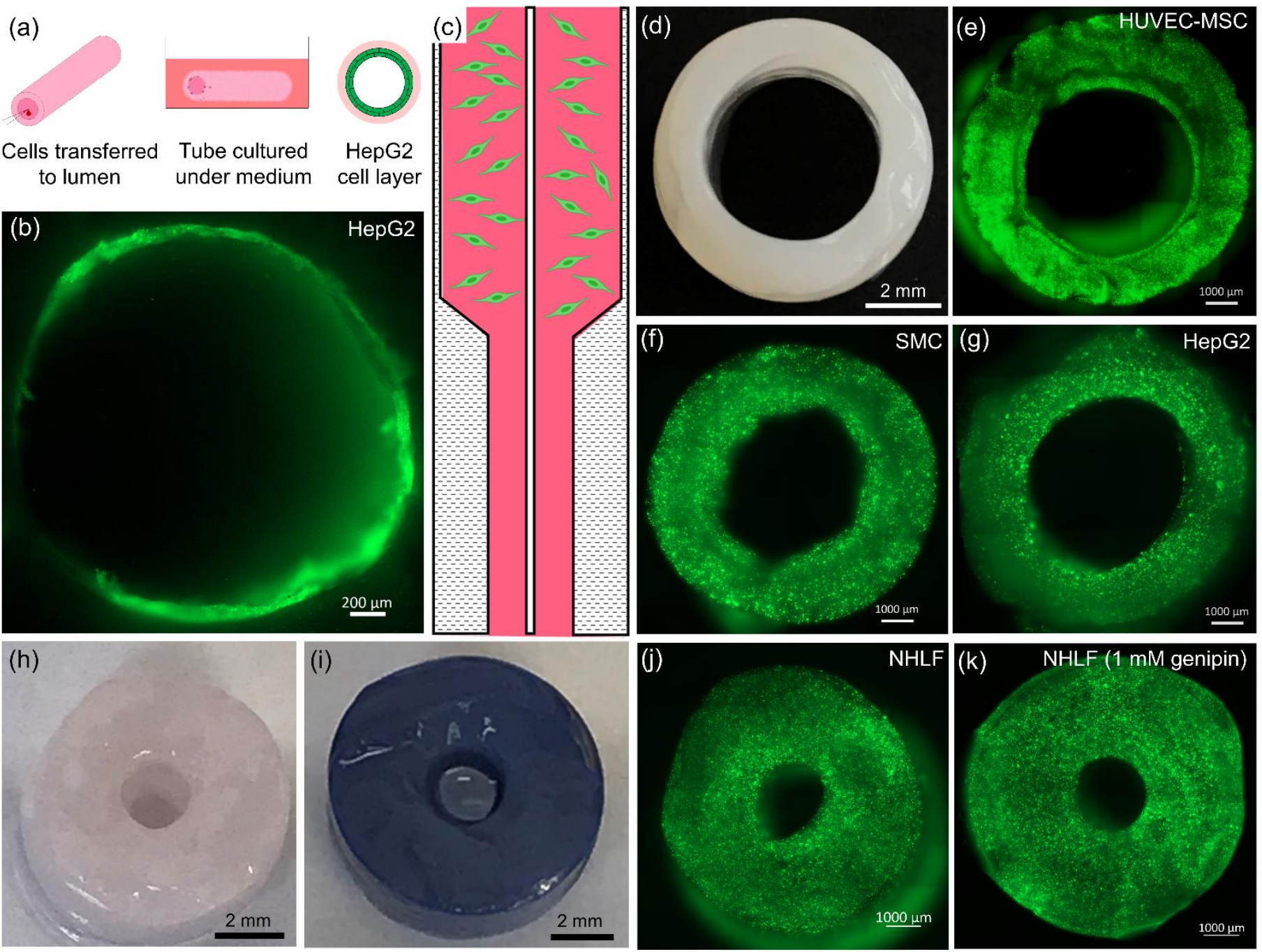

Figure 4: (a) Schematic of surface seeding process. HepG2s were pipetted into lumen of tube and cultured under medium for 1 week. (b) This led to formation of monolayer of cells on the luminal surface. (c) Schematic showing bulk cell seeding process (Funnel B). Cells were mixed into the funnel volume of the precursor gel solution. (d) Crosssectional image of $5 \mathrm{~mm}$ luminal diameter tube. (e) HUVECs and MSCs, (f) SMCs, and (g) HepG2s were encapsulated into the walls of a $5 \mathrm{~mm}$ luminal diameter tube. Samples of NHLF-seeded $2 \mathrm{~mm}$ luminal diameter tube (h) before and (i) after $1 \mathrm{mM}$ genipin crosslinking. NHLF-seeded $2 \mathrm{~mm}$ luminal diameter tubes showing high viability of cell population (j) before and (k) after $1 \mathrm{mM}$ genipin crosslinking. All cells were stained using calcein AM (green). 


\subsection{Seeding of cells onto luminal surface and into walls of densified collagen tubes}

Immunofluorescent hepatic epithelial cells (HepG2s) were seeded onto the luminal surface of the collagen tubes and produced a monolayer structure after 1 week of culture (Figure 4(a,b)). The method also allows cells to be uniformly seeded into the walls of the densified collagen tubes through encapsulation in the initial undensified collagen gel (Figure 4(c)). To demonstrate this, experiments were undertaken in which populations of human umbilical vein endothelial cells (HUVECs) and mesenchymal stem cells (MSCs), normal human lung fibroblasts (NHLFs), or smooth muscle cells (SMCs) were added to the precursor collagen solution, which was subsequently gelled and densified overnight (Figure $4(\mathrm{~d}-\mathrm{g})$ ). Sedimentation of these cells in the precursor gel solution was avoided by using $5 \mathrm{mg} / \mathrm{mL}$ collagen gel which had a suitable viscosity to slow this process and gelled rapidly upon heating to $37^{\circ} \mathrm{C}$. This yielded tubes in which cells were uniformly distributed through the walls of the tubes, for both 2 and $5 \mathrm{~mm}$ wall thicknesses. Genipin caused a significant colour change in the densified collagen tubes (Figure 4(h,i)). To test the biocompatibility of the crosslinker, a representative cellularised densified collagen tube was immersed in a $1 \mathrm{mM}$ genipin solution for $24 \mathrm{~h}$ and showed that the cells maintained their viability (Figure $4(\mathrm{j}, \mathrm{k})$ ).
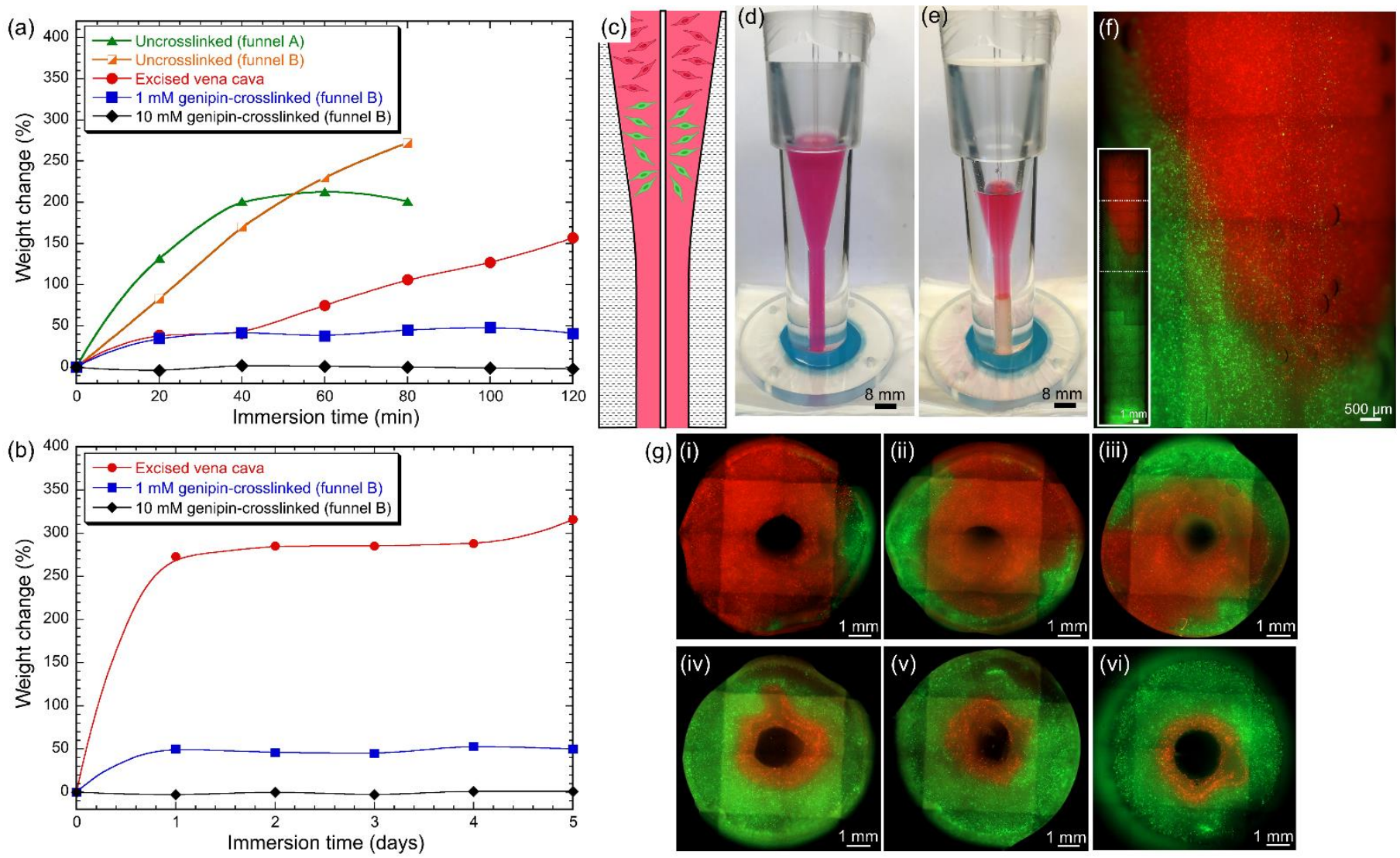

(g) (i)
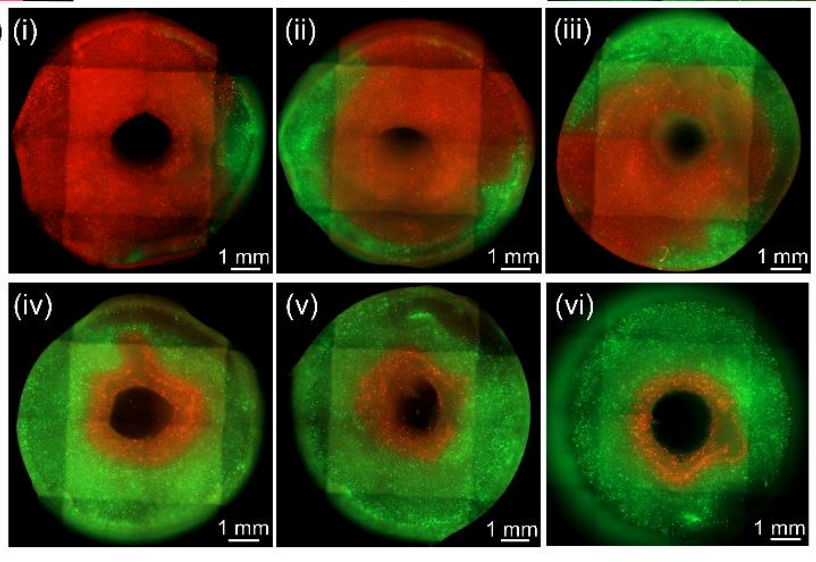

Figure 5: Acid solubility data obtained from immersion in $100 \mathrm{mM}$ acetic acid solution showing percentage change in weight over (a) a $2 \mathrm{~h}$ period, for crosslinked and uncrosslinked tube samples, and excised pig vena cava; and (b) a 5day period for crosslinked tube samples and excised pig vena cava. (c) Schematic showing position of green and red fluorescently-labelled cells (GFP and RFP HUVECs respectively) in undensified collagen gel. Collagen tube manufacture using two distinct cell domains showing (d) before densification and (e) after densification. (f) Interface between two cell domains in densified collagen tube. Inset shows whole collagen tube. (g)(i-vi) Cross-sectional views moving down the densified collagen tube, showing transition from RFP to GFP HUVECs. Note that due to the densification process, RFP HUVECs are transformed from the top of the gel to wrap around the lumen, even in the GFP HUVEC region of the tube. 


\subsection{Genipin-crosslinked densified collagen tubes are stable in acidic conditions}

As expected, uncrosslinked samples of densified collagen tube swelled significantly when transferred from PBS to $100 \mathrm{mM}$ acetic acid solution and dissolved within $2 \mathrm{~h}$ (Figure 5(a)). However, once crosslinked with genipin, this dissolution behaviour was prevented. $1 \mathrm{mM}$ genipin was sufficient to prevent the dissolution of the tubes, which underwent only limited swelling. Crosslinking with $10 \mathrm{mM}$ genipin eliminated the swelling of the tubes entirely, as shown over several days (Figure 5(b)). These tubes were compared to excised, intact pig vena cava samples which, while not dissolving in acid, underwent a high degree of swelling over several days.

\subsection{Generation of densified collagen tubes with two distinct cell domains}

Disease modelling applications may require the formation of a densified collagen tube with two distinct regions consisting of two different cell types (e.g. two different types of smooth muscle cell). Thus, tubes were manufactured casting half the precursor solution with one cell type and casting the second half of the precursor solution with the second cell type (Figure 5(c-e)). Cells from each sub-population were maintained in place by the high viscosity of the precursor gel solution prior to the gelation process. Cross-sectional views revealed two distinct cell domains consisting of either green or red fluorescently-labelled HUVECs (Figure 5(f)). Interestingly, the non-trivial mapping of the initial undensified collagen gel in the funnel section to the final densified collagen tube in the cylindrical section was such that the top group of HUVECs was located around the lumen while the bottom group of HUVECs populated the outer part of the walls, near the boundary between the cell domains (Figure $5(\mathrm{~g})(\mathrm{i}-\mathrm{vi})$ ).

(a)
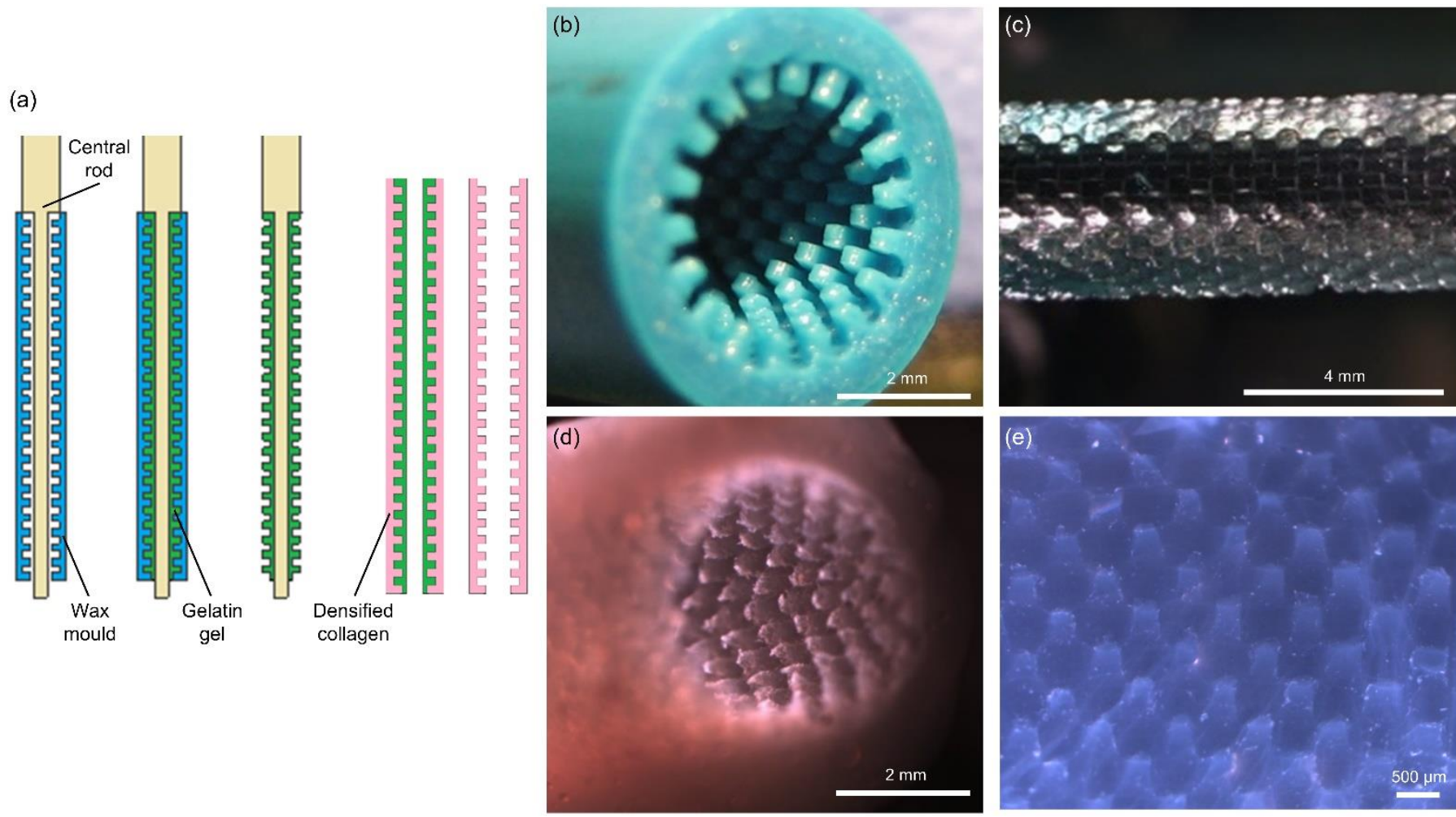

Figure 6: (a) Schematic showing luminal surface patterning process. Wax mould (blue) is mounted on a central rod with a cutaway. Wax mould is filled with gelatin gel (green) and the wax mould removed. After densification, the central rod is removed and the gelatin melted out of the densified collagen tube (pink). (b) 3D printed wax mould with patterned luminal features. (c) Gelatin gel inverse features, mounted on central rod. (d) Densified collagen tube with luminal surface features. (e) Luminal surface features at higher magnification.

\subsection{Generation of densified collagen tubes with luminal surface patterning}

Intestinal applications of the tubes may require the generation of crypt-villus structure on the luminal surface to promote efficient exchange of nutrients. To this end, we developed a process for patterning 3D printed structures in gelatin gel 
which, following casting and densification of the collagen, generated a regular pattern of villi-like structures, with crosssections of $250 \mu \mathrm{m}$ and heights of $500 \mu \mathrm{m}$ (Figure 6(a-e)). However, large features height can hold up the densification process as the collagen fibrils is unable to deform around such features.

\section{DISCUSSION}

Inadequate donor tissue supply to meet growing clinical need poses a significant problem to healthcare systems worldwide. Thus, we seek methods to produce new tissues and organs in the lab, which are custom-made, patient specific and clinical ready for use. A wide range of complex and patient-derived cellular structures, including organoids, can now be grown under 3D cell culture conditions, for tissues such as the coronary artery, bile duct, gastro-intestinal and genitourinary systems. However, there is a need to generate biomimetic, bioactive, and mechanically robust scaffolds on which to deploy these cells in a therapeutic clinical setting. The cellular micro-environment of the scaffold must enable attachment, proliferation, differentiation, and ultimately, remodelling and replacement of the scaffold itself by native tissue. Further, scaffolds with a suitable mechanical strength and a perfusable vasculature will be required to meet this objective.

In solutions of neutral $\mathrm{pH}$ and sufficient ionic content, the collagen biopolymer is able, through multiple fibrillar selfassembly steps, to form a stable hydrogel consisting of solid phase fibrillar network and a trapped aqueous phase. These fibrils are capable of permanent reorganisation under an external stimulus, such as when the liquid phase of the gel is removed (e.g. by evaporation), which leads to a significant increase in the mechanical strength of the scaffold. Such a reduction in the percentage of water in the hydrogel would also more closely resemble the hydration level of real tissue. By extracting the aqueous phase, the gel undergoes a large and irreversible deformation, from an initial low density, random fibrillar state, to a high density, aligned fibrillar state $[49,50]$. This syneresis is common to collagen gels; cells encapsulated in such gels impart forces upon the fibrillar structure which leads to the liquid phase being expelled from the gel [51, 52]. External, uniaxial loads applied to collagen gels also lead to expulsion of the liquid phase through the re-organisation of the fibrillar structure $[53,54]$. In our process, the use of a particular funnel geometry, and membrane assembly with which to anchor the collagen gel, allows us to contract the collagen gel into a useful tubular construct and control the distribution and alignment of the collagen fibrils, which can produce tubes of uniform density or with a density gradient along their length. While not useful for generating tissue equivalents, collagen gels with a gradient in fibril density may find other applications in bioengineering.

As shown when regions of collagen gel are labelled with two types of fluorescent cells, the particular mapping of volume elements from the funnel into the final cylindrical form is non-trivial; elements near the central rod are drawn down inside the surrounding gel due to the shape of the funnel. We also observe an expulsion of water from the top of the densifying gel (while we extract water from the base of the gel). As the collagen gel contracts downwards, it is likely due to the reorganisation of the fibrillar structure leads to water being forced out of the pores, which collects on top of the gel.

Through our densification process, collagen scaffolds can be fabricated to a wide range of diameters and wall thicknesses, consisting of highly aligned and bioactive collagen. The nature of the process allows for uniform cell encapsulation in the walls of the scaffold and also onto the surface, enabling more complex cellular arrangements to be manufactured. Since the densification process reduces the volume of the gel significantly, the cell density can be substantially increased. Unlike other methods for producing collagen tubes, this process produces seamless vessels with a self-supporting lumen. Finally, we have shown that through minor modifications, additional features can be incorporated into the structure such as 3D printing-based luminal surface patterning, and that through sequential collagen casting, one can build a collagen gel scaffold with multiple cell domains, useful for future disease modelling. 
The multi-domain tubes may find future application as a means of studying aortic aneurysms. The spatial organisation of the domains near the boundary, with one type populating the region near the lumen and the other type populating the outer wall region, is highly reminiscent of the pattern of distribution of SMCs in the proximal aorta at the boundary between SMCs of neural crest origin and lateral plate mesoderm [55]. Indeed, this overlapping pattern is thought to be one of the reasons why aortic aneurysms are prevalent in the aortic root and ascending aorta [56]. Thus, this manufacturing technique may in future allow us to recreate the distinct cellular spatial configurations in the proximal aorta.

Attempts at densifying collagen in a tall cylindrical mould failed due to the high surface area contact between collagen gel and chamber which produced a high degree of friction, and problems maintaining the central rod in the centre of the chamber. The funnel geometry enables the densification process to be performed in a standard incubator, which allows for faster water removal and provides the suitable temperature and $\mathrm{CO}_{2}$ environment for cell culture in the densifying collagen.

While efforts were made to eliminate trapped air bubbles in the tubes through centrifugation and careful pouring of the precursor solution, we were unable to eliminate them entirely. It is energetically favourable for air bubbles to form on the walls of the chamber rather than in the bulk of the collagen due to surface tension. Further, the solubility of gases in liquid is temperature dependent and thus at $37^{\circ} \mathrm{C}$ incubator temperatures, gas is released from the aqueous phase causing air bubbles to grow. This leads to air bubbles forming predominantly at the edges of the tube, leading to minor pits in the surface of the final densified collagen tubes. Air bubbles were a particular problem in early experiments where any perturbation to the nylon membrane would enable significant volumes of air bubbles to infiltrate the collagen solution through the membrane prior to gelling. Any infiltration of large air bubbles through the membrane after gelation of the collagen would be catastrophic to the densification process as it would cause a permeant displacement of the gel, often terminating the densification process by denying a path for water flow out of the gel and chamber.

The densification chamber funnel was machined from Perspex and further polished to remove surface defects. We found that applying a lubricant (i.e. an oil layer) to the funnel surface, and central rod, was essential to producing densification since it lowered the friction with the chamber walls and may have helped to fill any surface defects. Without this layer, the friction of the gel with the funnel held up the collagen gel sufficiently to prevent the densification process. Similarly, the choice of material for the central rod was important; we investigated the use of Perspex, hydrophobic PTFE, and hydrophilic nylon. We found that while Perspex rods were suitable for use tubes of $2 \mathrm{~mm}$ luminal diameter and $2.5 \mathrm{~mm}$ wall thicknesses, the increased friction generated upon the collagen gel due to the higher surface area of a $5 \mathrm{~mm}$ diameter rod, used with a $1.5 \mathrm{~mm}$ wall thickness, was sufficient even with an oil layer to hold up the densification of the gel, and so PTFE or nylon rods were used in those cases. A nylon rod was found to enable the fastest densification, likely due to its hydrophilic nature allowing for the formation of a liquid boundary layer between nylon and collagen gel.

We also investigated other materials for the casting chamber. Chambers fabricated using extrusion-based 3D printing had a very high surface roughness (owing to the layer-by-layer extrusion process) which led to very rough final tubes. Chambers made of PTFE failed to produce axial densification; instead, the collagen densified radially inwards. It is thought this was due to the very low friction surface allowing water to flow out of the gel along the funnel surfaces rather than through the collagen gel. Glass chambers allowed the oil layer to run off too easily and were expensive to manufacture. Finally, the thermal expansion of the casting chamber may be important to the technique. Casting was 
performed at room temperature and the assembly was moved to the $37^{\circ} \mathrm{C}$ incubator for gelation and densification. It was possible to pre-warm the chamber prior to casting to minimise this effect, though this ran the risk of causing premature collagen gelation.

Genipin was used owing to its biocompatibility and ease of sourcing. Transglutaminase, while potentially even more biocompatible, is expensive to source in its pure form and as such, researchers tend to use a meat glue, consisting of other components such as sodium caseimate and maltodextrin. A heavy degree of crosslinking produces stiff and brittle densified collagen scaffolds. We seek to use the crosslinking only as a method of eliminating the acid solubility of the collagen, enabling sutures to hold well without creating leak paths under tension.

As future work, we intend to incorporate heparin into the collagen tubes which, along with a luminal cell layer, will help control the thrombogenicity of the collagen-based construct, making it suitable for use in vascular tissue engineering. To enhance the proliferation of cells in the walls of the densified collagen tubes, and to enable more complex tubular structures to be formed, we also seek to incorporate a perfusable vasculature into the walls of the tubes, through a 3D printing-based technique $[44,57]$. We are also interested in modelling how the funnel geometry determines the mapping of collagen gel into its final densified collagen tube form. We also hope to explore using different funnel geometries to produce collagen gels with a high variation in the collagen density across the structure, and also use these different funnel geometries alongside multiple cell domain tubes to imitate the spatial configurations found in the aorta, between different populations of smooth muscle cell.

It is likely that the densified collagen tubes can be implanted acellular, or soon after seeding with cells into the bulk gel and onto the luminal surface. However, for in vitro disease modelling and further maturation of the cellularised construct, the tubes can be mounted into a bioreactor culture rig. Due to the cellular remodelling and syneresis effects that cells impart upon gel scaffolds, it is likely that with high cell densities, that the wall thickness will reduce further. Culturing the tubes under such conditions will be investigated in future studies.

\section{CONCLUSIONS}

Tissue engineering seeks methods for the generation of tissue conduits for clinical replacement and disease modelling applications, which have suitable mechanical and biological properties. We have developed a novel method for the formation of densified collagen tubes de novo and at human length-scales, which are highly customisable, mechanically robust and seamless, into which cells can be uniformly seeded both into the walls and onto the luminal surface of the construct. Through genipin crosslinking, we are able to eliminate collagen swelling and dissolution in acidic conditions. We show that it is possible to form two distinct cell domains within the same densified collagen tube, displaying the complex mapping of collagen gel from its undensified to densified form. Finally, we report a method for luminal surface patterning of the densified collagen tubes to imitate physiological structures.

Author Contributions: AWJ conceived of, designed, and performed the densification method, analysed and interpreted associated results and prepared the manuscript. Tensile testing experiments: AEM, AWJ and S.B; Cell experiments: AWJ, JO and AGJ; visualisation: AWJ and AEM; reviewing and editing: SS and AEM; supervision: AEM. All authors gave final approval for publication.

Acknowledgements: Financial support for this work has come from the Engineering and Physical Sciences Research Council (EPSRC, EP/R511675/1), the Isaac Newton Trust and the Rosetrees Trust (M787). Financial support for AWJ and JO has been provided via EPSRC (EP/R511675/1) and a WD Armstrong Doctoral Fellowship, respectively. Support 
bioRxiv preprint doi: https://doi.org/10.1101/2021.02.05.429744; this version posted February 7, 2021. The copyright holder for this preprint (which was not certified by peer review) is the author/funder. All rights reserved. No reuse allowed without permission.

for SS via a BHF Senior Fellowship (FS/18/46/33663) is gratefully acknowledged. We wish to acknowledge Fadwa Joud of the Cancer Research UK, Cambridge Institute for second harmonic generation microscopy of densified collagen tube samples, and Peter J. Holt of the Wellcome-Medical Research Council Cambridge Stem Cell Institute, for smooth muscle cell culture. We also wish to acknowledge Stefan Savage for machining the Perspex funnels.

\section{REFERENCES}

1. Langer R, Vacanti J. Advances in tissue engineering. J Pediatr Surg. 2016;51(1):8-12.

2. Hoenig MR, Campbell GR, Rolfe BE, Campbell JH. Tissue-engineered blood vessels: alternative to autologous grafts? Arterioscler Thromb Vasc Biol. 2005;25(6):1128-34.

3. L'Heureux N, Dusserre N, Konig G, Victor B, Keire P, Wight TN, et al. Human tissue-engineered blood vessels for adult arterial revascularization. Nat Med. 2006;12(3):361-5.

4. Seifu DG, Purnama A, Mequanint K, Mantovani D. Small-diameter vascular tissue engineering. Nat Rev Cardiol. 2013;10(7):410-21.

5. Huang AH, Niklason LE. Engineering of arteries in vitro. Cell Mol Life Sci. 2014;71(11):2103-18.

6. Song HG, Rumma RT, Ozaki CK, Edelman ER, Chen CS. Vascular Tissue Engineering: Progress, Challenges, and Clinical Promise. Cell Stem Cell. 2018;22(3):340-54.

7. Sampaziotis F, Justin AW, Tysoe OC, Sawiak S, Godfrey EM, Upponi SS, et al. Reconstruction of the mouse extrahepatic biliary tree using primary human extrahepatic cholangiocyte organoids. Nat Med. 2017;23(8):954-63.

8. Justin AW, Saeb-Parsy K, Markaki AE, Vallier L, Sampaziotis F. Advances in the generation of bioengineered bile ducts. Biochim Biophys Acta Mol Basis Dis. 2018;1864(4 Pt B):1532-8.

9. Hori Y, Nakamura T, Matsumoto K, Kurokawa Y, Satomi S, Shimizu Y. Tissue Engineering of the Small Intestine by Acellular Collagen Sponge Scaffold Grafting. The International Journal of Artificial Organs. 2001;24(1):50-4.

10. Grikscheit TC, Ochoa ER, Ramsanahie A, Alsberg E, Mooney D, Whang EE, et al. Tissue-engineered large intestine resembles native colon with appropriate in vitro physiology and architecture. Ann Surg. 2003;238(1):35-41.

11. Martin LY, Ladd MR, Werts A, Sodhi CP, March JC, Hackam DJ. Tissue engineering for the treatment of short bowel syndrome in children. Pediatr Res. 2018;83(1-2):249-57.

12. Poghosyan $\mathrm{T}$, Catry J, Luong-Nguyen M, Bruneval $\mathrm{P}$, Domet $\mathrm{T}$, Arakelian $\mathrm{L}$, et al. Esophageal tissue engineering: Current status and perspectives. J Visc Surg. 2016;153(1):21-9.

13. Arakelian L, Kanai N, Dua K, Durand M, Cattan P, Ohki T. Esophageal tissue engineering: from bench to bedside. Ann N Y Acad Sci. 2018;1434(1):156-63.

14. Atala A. Tissue engineering for the replacement of organ function in the genitourinary system. American Journal of Transplantation. 2004;4(s6):58-73.

15. Macchiarini $P$, Jungebluth $P$, Go $T$, Asnaghi MA, Rees LE, Cogan TA, et al. Clinical transplantation of a tissueengineered airway. The Lancet. 2008;372(9655):2023-30.

16. O'Leary C, Gilbert JL, O'Dea S, O'Brien FJ, Cryan SA. Respiratory Tissue Engineering: Current Status and Opportunities for the Future. Tissue Eng Part B Rev. 2015;21(4):323-44.

17. Goh CS, Joethy JV, Tan BK, Wong M. Large animal models for long-segment tracheal reconstruction: a systematic review. J Surg Res. 2018;231:140-53.

18. Udelsman B, Mathisen DJ, Ott HC. A reassessment of tracheal substitutes-a systematic review. Ann Cardiothorac Surg. 2018;7(2):175-82.

19. Wangensteen KJ, Kalliainen LK. Collagen tube conduits in peripheral nerve repair: a retrospective analysis. Hand (N Y). 2010;5(3):273-7.

20. Chwalek K, Tsurkan MV, Freudenberg U, Werner C. Glycosaminoglycan-based hydrogels to modulate heterocellular communication in in vitro angiogenesis models. Sci Rep. 2014;4:4414.

21. McCoy MG, Wei JM, Choi S, Goerger JP, Zipfel W, Fischbach C. Collagen Fiber Orientation Regulates 3D Vascular Network Formation and Alignment. ACS Biomater Sci Eng. 2018;4(8):2967-76.

22. Wimmer RA, Leopoldi A, Aichinger M, Wick N, Hantusch B, Novatchkova M, et al. Human blood vessel organoids as a model of diabetic vasculopathy. Nature. 2019;565(7740):505-10.

23. Bennett MR, Sinha S, Owens GK. Vascular Smooth Muscle Cells in Atherosclerosis. Circ Res. 2016;118(4):692702.

24. Granata A, Serrano F, Bernard WG, McNamara M, Low L, Sastry P, et al. An iPSC-derived vascular model of Marfan syndrome identifies key mediators of smooth muscle cell death. Nat Genet. 2017;49(1):97-109. 
bioRxiv preprint doi: https://doi.org/10.1101/2021.02.05.429744; this version posted February 7, 2021. The copyright holder for this preprint (which was not certified by peer review) is the author/funder. All rights reserved. No reuse allowed without permission.

25. Jung $\mathrm{Y}$, Ji H, Chen Z, Fai Chan H, Atchison L, Klitzman B, et al. Scaffold-free, Human Mesenchymal Stem CellBased Tissue Engineered Blood Vessels. Sci Rep. 2015;5:15116.

26. Norotte C, Marga FS, Niklason LE, Forgacs G. Scaffold-free vascular tissue engineering using bioprinting. Biomaterials. 2009;30(30):5910-7.

27. Quint C, Kondo Y, Manson RJ, Lawson JH, Dardik A, Niklason LE. Decellularized tissue-engineered blood vessel as an arterial conduit. Proc Natl Acad Sci U S A. 2011;108(22):9214-9.

28. Dahl SLM, Kypson AP, Lawson JH, Blum JL, Strader JT, Li Y, et al. Readily Available Tissue-Engineered Vascular Grafts. Science Translational Medicine. 2011;3(68):68ra9-ra9.

29. Kirkton RD, Santiago-Maysonet M, Lawson JH, Tente WE, Dahl SLM, Niklason LE, et al. Bioengineered human acellular vessels recellularize and evolve into living blood vessels after human implantation. Science Translational Medicine. 2019;11(485):eaau6934.

30. Tachibana M, Nagamatsu GR, Addonizio JC. Ureteral Replacement Using Collagen Sponge Tube Grafts. Journal of Urology. 1985;133(5):866-9.

31. Boland ED, Matthews JA, Pawlowski KJ, Simpson DG, Wnek GE, Bowlin GL. Electrospinning collagen and elastin: preliminary vascular tissue engineering. Frontiers in bioscience : a journal and virtual library. 2004;9:1422-32.

32. Nakamura T, Inada Y, Fukuda S, Yoshitani M, Nakada A, Itoi S, et al. Experimental study on the regeneration of peripheral nerve gaps through a polyglycolic acid-collagen (PGA-collagen) tube. Brain Res. 2004;1027(1-2):18-29.

33. Seliktar D, Black RA, Vito RP, Nerem RM. Dynamic Mechanical Conditioning of Collagen-Gel Blood Vessel Constructs Induces Remodeling In Vitro. Annals of Biomedical Engineering. 2000;28(4):351-62.

34. Brown RA, Wiseman M, Chuo C-B, Cheema U, Nazhat SN. Ultrarapid Engineering of Biomimetic Materials and Tissues: Fabrication of Nano- and Microstructures by Plastic Compression. Advanced Functional Materials. 2005;15(11):1762-70.

35. Isenberg BC, Williams C, Tranquillo RT. Small-diameter artificial arteries engineered in vitro. Circ Res. 2006;98(1):25-35.

36. Micol LA, Ananta M, Engelhardt EM, Mudera VC, Brown RA, Hubbell JA, et al. High-density collagen gel tubes as a matrix for primary human bladder smooth muscle cells. Biomaterials. 2011;32(6):1543-8.

37. Ghezzi CE, Marelli B, Muja N, Nazhat SN. Immediate production of a tubular dense collagen construct with bioinspired mechanical properties. Acta Biomater. 2012;8(5):1813-25.

38. Loy $C$, Laine A, Mantovani D. Rotation-based technique for the rapid densification of tubular collagen gel scaffolds. Biotechnol J. 2016;11(12):1673-9.

39. Li X, Xu J, Bartolák-Suki E, Jiang J, Tien J. Evaluation of 1-mm-diameter endothelialized dense collagen tubes in vascular microsurgery. Journal of biomedical materials research Part B, Applied biomaterials. 2020;108(6):2441-9.

40. Rajan N, Habermehl J, Cote MF, Doillon CJ, Mantovani D. Preparation of ready-to-use, storable and reconstituted type I collagen from rat tail tendon for tissue engineering applications. Nat Protoc. 2006;1(6):2753-8.

41. Tysoe OC, Justin AW, Brevini T, Chen SE, Mahbubani KT, Frank AK, et al. Isolation and propagation of primary human cholangiocyte organoids for the generation of bioengineered biliary tissue. Nat Protoc. 2019;14(6):1884-925.

42. Cheung C, Bernardo AS, Pedersen RA, Sinha S. Directed differentiation of embryonic origin-specific vascular smooth muscle subtypes from human pluripotent stem cells. Nat Protoc. 2014;9(4):929-38.

43. Serrano F, Bernard WG, Granata A, lyer D, Steventon B, Kim M, et al. A Novel Human Pluripotent Stem CellDerived Neural Crest Model of Treacher Collins Syndrome Shows Defects in Cell Death and Migration. Stem Cells Dev. 2019;28(2):81-100.

44. Justin AW, Brooks RA, Markaki AE. Multi-casting approach for vascular networks in cellularized hydrogels. J R Soc Interface. 2016;13(125).

45. Berglund JD, Mohseni MM, Nerem RM, Sambanis A. A biological hybrid model for collagen-based tissue engineered vascular constructs. Biomaterials. 2003;24(7):1241-54.

46. Cheema U, Chuo CB, Sarathchandra P, Nazhat SN, Brown RA. Engineering Functional Collagen Scaffolds: Cyclical Loading Increases Material Strength and Fibril Aggregation. Advanced Functional Materials. 2007;17(14):242631.

47. Madhavan K, Belchenko D, Motta A, Tan W. Evaluation of composition and crosslinking effects on collagen-based composite constructs. Acta Biomater. 2010;6(4):1413-22.

48. Madhavan $\mathrm{K}$, Belchenko D, Tan W. Roles of genipin crosslinking and biomolecule conditioning in collagen-based biopolymer: Potential for vascular media regeneration. J Biomed Mater Res A. 2011;97(1):16-26.

49. Liu Z, Toh W, Ng TY. Advances in Mechanics of Soft Materials: A Review of Large Deformation Behavior of Hydrogels. International Journal of Applied Mechanics. 2015;07(05):1530001.

50. Lai VK, Nedrelow DS, Lake SP, Kim B, Weiss EM, Tranquillo RT, et al. Swelling of Collagen-Hyaluronic Acid CoGels: An In Vitro Residual Stress Model. Ann Biomed Eng. 2016;44(10):2984-93. 
51. Hadjipanayi E, Ananta M, Binkowski M, Streeter I, Lu Z, Cui ZF, et al. Mechanisms of structure generation during plastic compression of nanofibrillar collagen hydrogel scaffolds: towards engineering of collagen. $\mathrm{J}$ Tissue Eng Regen Med. 2011;5(7):505-19.

52. Ban E, Franklin JM, Nam S, Smith LR, Wang H, Wells RG, et al. Mechanisms of Plastic Deformation in Collagen Networks Induced by Cellular Forces. Biophys J. 2018;114(2):450-61.

53. Knapp DM, Barocas VH, Moon AG, Yoo K, Petzold LR, Tranquillo RT. Rheology of reconstituted type I collagen gel in confined compression. Journal of Rheology. 1997;41(5):971-93.

54. Tang Y, Ballarini R, Buehler MJ, Eppell SJ. Deformation micromechanisms of collagen fibrils under uniaxial tension. J R Soc Interface. 2010;7(46):839-50.

55. Sawada H, Rateri DL, Moorleghen JJ, Majesky MW, Daugherty A. Smooth Muscle Cells Derived From Second Heart Field and Cardiac Neural Crest Reside in Spatially Distinct Domains in the Media of the Ascending Aorta-Brief Report. Arterioscler Thromb Vasc Biol. 2017;37(9):1722-6.

56. Davaapil H, Shetty DK, Sinha S. Aortic "Disease-in-a-Dish": Mechanistic Insights and Drug Development Using iPSC-Based Disease Modeling. Front Cell Dev Biol. 2020;8:550504.

57. Guy AA, Justin AW, Aguilar-Garza DM, Markaki AE. 3D Printable Vascular Networks Generated by Accelerated Constrained Constructive Optimization for Tissue Engineering. IEEE Trans Biomed Eng. 2020;67(6):1650-63. 